\title{
A PREVENÇÃO A APATRIDIA NO CONTEXTO INTERNACIONAL
}

\author{
Cássio Eduardo Zen ${ }^{1}$
}

\section{RESUMO}

O artigo propõe avaliar a questão da apatridia, em especial a prevenção desta no ramo do Direito Internacional, como norma imperativa de proteção da própria dignidade do indivíduo. Para tanto, é realizada introdução ao tema, com exposição dos principais problemas derivados da apatridia, conceituação da apatridia, de norma imperativa de direito internacional e análise de documentos internacionais relevantes. Finalmente é realizado relato da situação dos brasileiros nascidos fora do Brasil e que, dadas as circunstâncias absurdas da Constituição Federal, tornam-se apátridas.

\section{ABSTRACT}

This article proposes to evaluate the question of statelessness, specially its prevention on the International Law field. To reach this objective the articles is divided $\mathrm{n}$ some areas, such as the introduction, explaining the main problems derived from statelessness, the concepts of statelessness and imperative rules of International Law and International Documents analysis. Finally, we approach the case of Brazilians born outside Brazil and due absurd circumstances of Brazilian Constitution, became statelessness.

\footnotetext{
${ }^{1}$ Acadêmico de Direito da Universidade Federal do Paraná, bolsista extensionista do Núcleo de Estudos em Direito Internacional da Universidade Federal do Paraná, editor da Revista Brasileira de Direito Internacional e participante dos Cursos de Verão da Academia de Direito Internacional da Haia, 2007. Dedica-se este artigo àqueles que sabem o verdadeiro significado da expressão: "De volgende haute: Konradkade" (quando lerem, lembrarão).
}

Revista Brasileira de Direito Internacional, Curitiba, v.5, n.5, jan./jun.2007 


\section{INTRODUÇÃO}

"There is an urge and rage in people to destroy, to kill, to murder, and until all mankind, without exception, undergoes a great change, wars will be waged, everything that has been built up, cultivated and grown, will be destroyed and disfigured, after which mankind will have to begin all over again."

Anne Marie Frank (1929-1944)

A apatridia é problema cada vez mais grave no mundo em que vivemos, em especial pelas fortes correntes de emigração. A apatridia acarreta sérios prejuízos ao indivíduo que não tem reconhecidos direitos políticos, não recebe proteção internacional de Estado algum e é tratado como estrangeiro não importa onde esteja.

Outra estirpe de problemas causados pela apatridia é a de ausência de reconhecimento como nacional. Desta maneira, o indivíduo não pode retirar documentos, como por exemplo, o passaporte nacional ${ }^{2}$, carteira nacional de identidade. Tais privações podem impedir o indivíduo de trabalhar, de realizar operações financeiras, de assinar um contrato, coisas que são fundamentais em nossa sociedade.

Mais grave, a apatridia ceifa a possibilidade do indivíduo identificar-se com um Estado, mesmo que culturalmente e sentimentalmente haja alguma ligação, pois tais vínculos nem sempre são reconhecidos juridicamente. Tal possibilidade traz graves danos à dignidade do indivíduo, que é considerado menos nacional, menos brasileiro, menos suíço, menos italiano, enfim, um não nacional, um ser de categoria inferior.

Assim, num exemplo cotidiano, o indivíduo filho de brasileiros nascido fora do Brasil, que fale português, leia Machado de Assis, prepare feijoada ou churrasco, beba caipirinha, sinta-se brasileiro, pode não ser reconhecido pelo Estado brasileiro como tal. Ressalta-se que mesmo que o indivíduo não falasse português, não lesse Machado de Assis, não preparasse feijoada ou churrasco e nem bebesse caipirinha, teria ele o direito de ser reconhecido brasileiro por demonstrar conexão com o Estado do Brasil, pois lei alguma no Brasil restringe

\footnotetext{
${ }^{2}$ Embora seja possível no caso dos apátridas obter o conhecido passaporte amarelo, das Nações Unidas, mediante solicitação ao Alto Comissariado de Direitos Humanos.
}

Revista Brasileira de Direito Internacional, Curitiba, v.5, n.5, jan./jun.2007 
a atribuição de nacionalidade brasileira aos indivíduos que saibam preparar uma feijoada, por mais que tal prato seja reconhecida parte da cultura brasileira. Isto sem contar a multiculturalidade do Brasil, um país formado por diversas culturas diversas, convergindo para uma miscigenação nacional.

Mais grave ainda, a apatridia pode ser utilizada como punição por regimes ditatoriais inescrupulosos. Tornando o indivíduo um não nacional por motivos políticos é algo completamente antidemocrático e atentatório a dignidade da pessoal humana. Trata-se do sonho de qualquer ditador, no caso de uma pseudo-eleição ameaçada por um oposicionista "rebelde" simplesmente cassar os direitos políticos de seu rival através da retirada da nacionalidade do mesmo. Quando tal procedimento é realizado contra um grupo de pessoas, a situação torna-se pior ainda.

Alguns Estados prevêem concessão de asilo político a apátridas, como a Armênia, que prevê em sua legislação a concessão de asilo político aos apátridas vítimas de persecução política em seus Estados de Origem ${ }^{3}$. Outro caso que vale a menção é o do Cazaquistão, que confere asilo político ao apátrida e sua família que sejam vítimas de persecução de seu país de residência por atividades públicas e políticas, raça, nacionalidade, religião e também no caso de infrações aos direitos humanos ${ }^{4}$.

A proteção internacional da pessoa humana deve englobar a proteção do apátrida que, mesmo não sendo nacional de Estado algum, deve ter sua integridade, sua cultura e sua nacionalidade ${ }^{5}$ preservada. A organização Human Rights Watch afirma que:

"Os direitos e necessidades especiais de proteção de crianças
refugiadas, imigrantes e apátridas foram frequentemente
negligenciadas. Entre as mais vulneráveis do mundo, estas crianças
foram frequentemente submetidas a condições perigosas ou lesivas de
trabalho, violência sexual e outros abusos físicos, negação de

\footnotetext{
${ }^{3}$ ARMÊNIA. The Law of The Republic of Armenia on Political Asylum, article 3.1.

${ }^{4}$ CAZAQUISTÃO. Presidential Decree July 15 1996, article 3.

${ }^{5}$ Utilizamos o termo nacionalidade neste caso simbolizando o pertencer a uma nação, não com pertencer a um Estado. Alguns autores consideram esta faceta a porção sociológica da nação, mas nós consideramos a cultura como elemento integral da própria nação.
}

Revista Brasileira de Direito Internacional, Curitiba, v.5, n.5, jan./jun.2007 
educação e saúde e outras violações de seus direitos humanos fundamentais."

Continua a mesma organização em seu relatório de 2002, sobre violações ocorridas em Estados desenvolvidos e com democracias consolidadas, demonstrando que as violações de direitos de apátridas, especialmente crianças, não é uma exclusividade dos países pobres e/ou ditatoriais. O primeiro exemplo é quanto a detenções efetuadas nos Estados Unidos da América:

\begin{abstract}
"Nos Estados Unidos, o Serviço de Naturalização e Imigração (SNI) continuou a deter uma proporção substancial de crianças desacompanhadas em instalações com formato de cadeias, em certos casos mantendo-os em celas com criminosos juvenis. A agência foi criticada por negar acesso total a inspetores independentes, incluindo a Comissão Feminina para Mulheres e Crianças Refugiadas e a advogados que representavam crianças detidas em uma bem sucedida ação coletiva que contestava as condições de confinamento para jovens sob custódia do SNI. Num bom progresso, Senadora Dianne Feinstein propôs legislação que corrigiria esta e outras condições abusivas para crianças desacompanhadas nos Estados Unidos." ${ }^{\prime 7}$
\end{abstract}

Continuando, cita-se outro caso, na Grécia, onde crianças foram excluídas de processo de legalização ofertado pelo Governo grego:

"Na Grécia, crianças desacompanhadas foram largamente excluídas de
participação no programa de 5 de julho a 2 de agosto que tornou legais
os imigrantes que poderiam provar que chegaram à Grécia antes de 2
de julho de 2000. Sob os termos do programa, migrantes
indocumentados que não poderiam dar extensa documentação de sua

\footnotetext{
${ }^{6}$ HUMAN RIGHTS WATCH. World Report 2001: Childrens's Rights - Refugee, Immigrant and Stateless Children. Original em Inglês: "The rights and special protection needs of refugee, immigrant, and stateless children were frequently neglected. Among the world's most vulnerable, these children were often subjected to hazardous or exploitative labor conditions, sexual violence and other physical abuse, denial of education and health care, and other violations of their basic human rights." (traduzimos)

${ }^{7}$ Human Rights Watch. World Report 2002: Children's Rights. Original em Inglês: "In the United States, the Immigration and Naturalization Service (INS) continued to detain a substantial proportion of the unaccompanied children in its custody in jail-like settings, sometimes holding them in cells with juvenile offenders. The agency was criticized for denying full access to independent monitors, including the Women's Commission for Refugee Women and Children and the lawyers who represented detained children in a successful class-action lawsuit challenging the conditions of confinement for youth in INS custody. In a positive development, Senator Dianne Feinstein proposed legislation that would correct these and other abusive conditions for unaccompanied children in the United States." (traduzimos)
}

Revista Brasileira de Direito Internacional, Curitiba, v.5, n.5, jan./jun.2007 
presença, incluindo prova de identidade, recibo de salários, pagamento de utilidades e outros que crianças desacompanhadas não poderiam ter eram submetidas a deportação forçada se não saíssem do país voluntariamente." 8

Importante notar que não se está avaliando a conduta dos referidos estados, que não nos cabe avaliar aqui. No entanto, tais atitudes governamentais demonstram o drama de ser apátrida, ou melhor, a situação delicada que se encontram.

Há ainda situações que refugiados tornam-se apátridas por decisão governamental. Um exemplo conhecido é o do Butão e do Nepal. No início da década de 90, diversos butaneses de origem nepalesa perderam suas nacionalidades butanesas por razões arbitrárias e forçados a refugiar-se no Nepal, chegando ao número de cem mil refugiados ${ }^{9}$.

Em 2003 os governos do Butão e do Nepal apresentaram uma, com a devida vênia, pseudo solução, ao afirmarem que alguns dos refugiados poderiam ser repatriados. Haveria uma divisão em categorias, o que fez com que de 12.000 refugiados num campo, somente 239 fossem considerados "aptos" a tornarem-se novamente butaneses, com todos os direitos daí advindos. ${ }^{10}$

Outra grande quantidade de indivíduos poderiam em casos especiais "recuperarem" suas nacionalidades, mas seus direitos derivados e propriedades ficariam numa situação incerta. Outros não poderiam ser renacionalizados. Ora, mesmo que essa porcentagem de indivíduos que poderia recuperar sua nacionalidade o consiga, tal conduta de separação de nacionais por categorias é reprovável e somente nos faz lembrar dos tempos da Alemanha Nazista, onde os judeus alemães eram considerados inferiores

\footnotetext{
${ }^{8}$ HUMAN RIGHTS WATCH. World Report 2002: Children's Rights. Original em Inglês: "In Greece, unaccompanied children were largely excluded from participation in the June 5 to August 2 program that gave legal status to undocumented immigrants who could prove they had arrived in Greece before June 2, 2000. Under the terms of the program, undocumented migrants who could not provide extensive documentation of their presence--including proof of identity, wage receipts, utility payment receipts, and other documents unaccompanied children could not be expected to have--were subject to forced deportation if they did not leave the country voluntarily." (traduzimos)

9 HUMAN RIGHTS WATCH. Buthanese Refugees Rendered Stateless (Human Rights Watch, 18-6-2003).

${ }^{10}$ HUMAN RIGHTS WATCH. Buthanese Refugees Rendered Stateless (Human Rights Watch, 18-6-2003).
}

Revista Brasileira de Direito Internacional, Curitiba, v.5, n.5, jan./jun.2007 
aos arianos alemães. Ou ainda, ao caso dos parias indianos, religiosamente excluídos por "não terem nascido do corpo de Brahma.

A violação foi tamanha no caso dos butaneses que Rachel REILLY, conselheira de política de refugiados da Human Rights Watch afirmou:

\footnotetext{
"Os refugiados butaneses esperaram por mais de uma década por uma solução ao seu apelo. Isto não é uma solução, mas uma completa violação de seus direitos"11
}

Uma solução mais efetiva para este caso foi apresentada pelos Estados Unidos da América, em medida louvável, ofereceu readaptação a cerca de sessenta mil refugiados. O Nepal prontificou-se a readaptar até oitenta e cinco mil refugiados. Outros países como Austrália, Canadá, Dinamarca, Noruega, Nova Zelândia e os Países Baixos também acenaram com a possibilidade de readaptação ${ }^{12}$.

Apesar de não ser o ideal (que seria a repatriação no Butão, com condições dignas), a readaptação permite um melhor desenvolvimento que um campo de refugiados oferece, assim como melhores condições de pleitear seu retorno ao Butão, como butaneses de direito. No entanto, esta possibilidade parece distante, como coloca Bill FRELICK:

\footnotetext{
"Repatriação normalmente é vista como a melhor opção para refugiados - mas somente quando as condições que causaram tal fuga mudaram suficientemente de maneira que possam retornar com segurança. O tratamento governamental de nepaleses étnicos que ainda vivem no Butão, demonstra que tais condições não existem. Eles continuam um grupo marginalizado com receio de serem despejados."13
}

\footnotetext{
${ }^{11}$ REILLY, Rachel. Nepal: Buthanese Refugees Rendered Stateless. In: HUMAN RIGHTS WATCH. Buthanese Refugees Rendered Stateless (Human Rights Watch, 18-6-2003). Original em Inglês: The Bhutanese refugees have been waiting over a decade for a solution to their plight. This is not a solution, but rather a wholesale violation of their rights."

DIXIT, Himali. Repatriation or resettlement. Resolving the Lhotshampa dilemma. Himal Southasian. Special Report june 2007.

${ }^{13}$ FRELICK, Bill. Bhutanese Refugees: The Right of Return, the Chance for Resettlement. The Huffington Post, 20 de junho de 2007. Original em Inglês: "Repatriation is generally regarded as the best option for refugees - but only when the conditions that caused them to flee have changed enough that they can return safely. The government's treatment of the ethnic Nepalis who still live in Bhutan, however, shows such conditions do not exist. They remain a marginalized group in constant fear that they too could be evicted" (traduzimos).
}

Revista Brasileira de Direito Internacional, Curitiba, v.5, n.5, jan./jun.2007 
Conclui então FRELICK, afirmando que apesar do direito de retornarem, devido as circunstâncias, ainda não é possível retornar ${ }^{14}$. Este caso demonstra claramente como os apátridas, por questão de lei ou por perseguição política, tem negados seus direitos básicos, como tem negada sua própria nacionalidade, sua origem. Eis a razão principal para um estudo aprofundado sobre a matéria.

${ }^{14}$ FRELICK, Bill. Bhutanese Refugees: The Right of Return, the Chance for Resettlement. The Huffington Post, 20 de junho de 2007.

Revista Brasileira de Direito Internacional, Curitiba, v.5, n.5, jan./jun.2007 


\section{CONCEITUANDO APATRIDIA}

Para conduzirmos este trabalho a conclusões proveitosas, necessário se faz estabelecer alguns conceitos, para em seguida tratar o direito a uma nacionalidade como norma imperativa. Após compreendido o problema, passaremos então a analisar como a apatridia vem sendo combatida pelos diversos Estados, seja de maneira unilateral, seja através de tratados multilaterais.

Conceitua-se a apatridia, de uma maneira geral, através de um conceito negativo: aquele que não tem pátria, ou melhor, aquele sem nacionalidade reconhecida por Estado algum. Definir-se ia, desta maneira, apátrida aquele sem nação, ou na melhor acepção anglo-saxã ${ }^{15}$ : sem Estado ${ }^{16}$. Isto diferenciaria o sujeito sem nação, que como veremos a diante não existiria completamente, do sujeito sem Estado ${ }^{17}$.

A natureza negativa deste conceito nos obriga a procurar o que é nacional, pergunta de difícil resposta. Antonio Sanchez de BUSTAMANTE Y SIRVEN define em conceito clássico a nacionalidade como "o vínculo jurídico e político que existe entre as pessoas e o Estado como origem e garantia de direitos e deveres recíprocos"18. Mais do que isso, consideramos necessário acrescentar a contribuição de Anthony BRADLEY e Keith EWING, para quem haveria uma relação privilegiada entre o sujeito e o Estado ${ }^{19}$.

Desta maneira, podemos apresentar, em que pese o caráter negativo do conceito a apatridia como o estado do indivíduo sem um vínculo que acarrete uma relação privilegiada com Estado algum. Para o Estado o impacto de não ter um indivíduo como componente de sua dimensão pessoal é

\footnotetext{
${ }^{15}$ Empregado por exemplo pela Refugees International - Organização destinada à proteção dos refugiados.

${ }^{16}$ Stateless.

17 Não há espaço neste trabalho, nem é pertinente divagarmos sobre a diferenciação entre Estado e nação. Para aqueles que desejam maiores informações do tema, sugerimos o nosso "Aspectos Culturais e a Regulamentação da Nacionalidade Originária".

${ }^{18}$ BUSTAMANTE Y SIRVEN, Antônio Sanchez de. Derecho Internacional Privado, t.1, p.224. Original em espanhol: "consiste en el vínculo jurídico y político que existe entre las personas y el Estado como origen y garantia de derechos y deberes recíprocos". (traduzimos)

${ }^{19}$ BRADLEY, Anthony; EWING, Keith. Constitutional and Administrative Law, p.431.
}

Revista Brasileira de Direito Internacional, Curitiba, v.5, n.5, jan./jun.2007 
consideravelmente menor que o impacto que não ter um Estado protetor causa a um indivíduo, ou até mesmo a um grupo de indivíduos.

Pierre MAYER e Vincent HEUZÉ afirmam que:

"A apatridia é a situação da pessoa que Estado algum considera como
advindo. Ela se caracteriza pela ausência de uma proteção
internacional por um Estado. Deve-se, então buscar a melhora do
estatuto do apátrida (A) e a prevenir a aparição de apatridia (B)." ${ }^{.20}$

Para Bernard AUDIT, tratam-se de situações de conflitos negativos em que ao indivíduo não é atribuída nacionalidade alguma ${ }^{21}$. A hipótese do conflito negativo é a menos cruel das formas de apatridia, a outra sendo a excisão da nacionalidade do indivíduo.

Diferencia-se a apatridia dos casos em que o indivíduo está vinculado a um determinado Estado, mesmo se considerando nacional não reconhecido de outro Estado. É o caso dos trentinos nascidos no Brasil, cuja nacionalidade italiana não é reconhecida diretamente pelo governo da Itália $^{22}$, mas possuem vínculo com outro Estado, no caso o Brasil. Estes casos, por mais prejudicial que possa ser ao indivíduo não ter uma nacionalidade reconhecida, há ao menos uma nacionalidade, não configurando a apatridia.

Também não configuram a apatridia os casos em que um grupo de indivíduos reclama pertencer a uma nação distinta do Estado que a controla. Por exemplo: não são apátridas os curdos turcos, por mais que almejem a autonomia perante a Turquia ou que não se considerem turcos, pois possuem o status de nacional turco, estão vinculados ao Estado turco.

No entanto, se há perseguição a determinado grupo cultural-étnico, como por exemplo mais conhecido o caso dos judeus alemãos no III Reich, há, sem dúvida alguma, questão de direitos humanos a ser averiguada. Mas trata-

${ }^{20}$ MAYER, Pierre ; HEUZÉ, Vincent. Droit International Prive, p.620. Original em francês: "L'apatridie est la situation de la personne qu'aucun État ne considère comme son ressortissant. Elle se caractérise par l'absence de protection internationale par un État. On a donc chercé à ameliorer le statut de l'apatride (A), et à prévenir l'apparition de l'apatridie." (traduzimos)

${ }^{21}$ AUDIT, Bernard. Droit International Privé, p.760-761.

${ }^{22}$ No caso dos trentinos que deixaram a Itália antes da eficácia do tratado de Saint Germain en Laye exige-se a comprovação de italianidade dos requerentes, não sendo um reconhecimento direto. Este caso é estudado em detalhes em nosso "Aspectos Culturais e a Regulamentação da Nacionalidade Originária".

Revista Brasileira de Direito Internacional, Curitiba, v.5, n.5, jan./jun.2007 
se de coisa distinta da apatridia, salvo casos em que a perseguição culmine com a retirada do status de nacional, como numa captis diminutia dos romanos, ou como já demonstramos ocorrido no caso dos butaneses de origem nepalesa. $O$ combate a discriminações é algo diverso do combate a apatridia, embora ambos os casos a atuação da comunidade internacional é fundamental para a garantia de direitos humanos consagrados.

A apatridia é tema que interessa da diferentes áreas do direito, sendo impossível listar a todas neste curto artigo. O direito internacional privado lida com as questões de lei aplicável nas diferentes situações jurídicas envolvendo os apátridas, o direito internacional público na maneira com que tais indivíduos são (mal)tratados na ordem internacional e o direito constitucional pois o indivíduo nacional é elemento constitutivo do próprio Estado. No entanto, neste artigo analisaremos a apatridia fundamentalmente no ramo internacional e dos direitos humanos.

Revista Brasileira de Direito Internacional, Curitiba, v.5, n.5, jan./jun.2007 


\section{NORMA IMPERATIVA, JUS COGENS E LOIS DE POLICE}

O conceito de Norma Imperativa é o de uma norma tão superior que ultrapassa a mera noção de obrigatória. Nos dizeres de Tatyana Scheila FRIEDRICH a "Norma Imperativa expressa uma ordem categórica, que ultrapassa a noção de norma obrigatória, porque, aquela é superior a esta. Todas as normas jurídicas são obrigatórias, a priori. ${ }^{\text {23 }}$

Portanto, podemos apontar a primeira característica de uma norma imperativa, que é pertencer a uma categoria separada, impositiva, que "não admitem atitudes nem acordos em contrário, e à qual os Estados devem se submeter", ainda no pensamento de FRIEDRICH ${ }^{24}$.

Se considerarmos então a prevenção da apatridia como norma imperativa, a atitude tomada pelo governo do Butão no caso dos butaneses de origem nepalesa, que analisamos no primeiro capítulo deste artigo, uma atitude ilícita, pois Estado algum pode agir da maneira que tal Estado atuou.

No entanto, é direito de um Estado determinar quem é seu nacional e quem não o é, sendo competência exclusiva de cada um determinar por sua legislação interna quais os critérios para atribuição de nacionalidade. Este princípio é consolidado no direito internacional, inclusive em diversas Convenções como o Código Bustamante ${ }^{25}$ e a Convenção da Haia de $1930^{26}$, apesar de tentativas de criar normas para prevenção da apatridia que invadiriam esta competência, algumas tentativas inclusive obtendo certo sucesso como veremos na etapa seguinte deste estudo.

Já o conceito de jus cogens pode ser considerado, ainda na concepção de FRIEDRICH, com a qual estamos de acordo: "o direito cogente que exprime as normas imperativas de direito internacional." ${ }^{27}$ A primeira aparição do jus cogens em textos normativos foi numa singela norma da Convenção de Viena

${ }^{23}$ FRIEDRICH, Tatyana Scheila. As Normas Imperativas de Direito Internacional Público jus cogens, p.32.

${ }^{24}$ FRIEDRICH, Tatyana Scheila. As Normas Imperativas de Direito Internacional Público jus cogens, p.24.

${ }^{25}$ CONVENÇÃO DE DIREITO INTERNACIONAL PRIVADO, Habana, 1928, art.9.

26 CONVENTION ON CERTAIN QUESTIONS RELATING TO THE CONFLICT OF NATIONALITY LAWS, Den Haag, 1930, art.1.

${ }^{27}$ FRIEDRICH, Tatyana Scheila. As Normas Imperativas de Direito Internacional Público jus cogens, p.25.

Revista Brasileira de Direito Internacional, Curitiba, v.5, n.5, jan./jun.2007 
de 1969, o artigo 53 que prevê a nulidade de um tratado que quando concluso contrarie norma peremptória de direito internacional geral ${ }^{28}$.

No ramo do direito internacional privado, as normas imperativas denominam-se lois de police, que não seriam aplicáveis aos apátridas, por tratarem de ramos de aplicação diferentes. Conceitua FRIEDRICH:

\begin{abstract}
“as normas imperativas de Direito Internacional Privado são aquelas regras de âmbito interno que contêm determinados assuntos considerados essenciais ao país que as promulgou e, por isso, são automaticamente aplicadas. Diante de casos concretos a ordenamentos jurídicos de mais de um país, elas têm o poder de afastar a busca pela legislação aplicável através do método conflitual, e assim, evitar o uso do direito estrangeiro, sendo aplicadas de imediato." ${ }^{29}$
\end{abstract}

Portanto, há uma diferença que importa informarmos. Em que pese 0 estudo do direito da nacionalidade e por conseqüência da apatridia no Direito Internacional Privado, as lois de police tratam-se de uma não aplicação do método conflitual dada a importância de certas normas imperativas, que impedem a aplicação do direito estrangeiro. Já o jus cogens trata de normas que o Estado não pode deixar de aplicar.

No caso dos apátridas, não se está a avaliar qual norma deve ser aplicada por efetivamente não haver conflito positivo de leis, mas conflito negativo de leis de nacionalidade. No caso dos apátridas "natos", ou seja, aqueles que já nascem nesta categoria e não são, portanto, "naturalizados apátridas" por governos tiranos ou deslocamento forçado (ou ainda pelas duas coisas juntas), não há lei aplicável e daí decorre a situação de apatridia.

Pelos problemas expostos e pela indissociável conexão entre os direitos humanos e o direito do indivíduo a uma nacionalidade. Este direito inclusive é postulado na Declaração Universal dos Direitos do Homem, das Nações Unidas, em seu artigo $15^{30}$, aliado a vedação à privação arbitrária da própria nacionalidade ${ }^{31}$. Ora, já demonstramos que há, basicamente, duas possibilidades de apatridia: a "nata", que seria combatida pelo direito de todo

\footnotetext{
${ }^{28}$ CONVENTION ON THE LAW OF TREATIES, Wien, 1969, art.53.

${ }^{29}$ FRIEDRICH, Tatyana Scheila. Normas Imperativas de Direito Internacional Privado lois de police, p.25.

${ }^{30}$ UNITED NATIONS, Universal Declaration of Human Rights, art.15, 1.

${ }^{31}$ UNITED NATIONS, Universal Declaration of Human Rights, art.15, 2.
}

Revista Brasileira de Direito Internacional, Curitiba, v.5, n.5, jan./jun.2007 
indivíduo a ter uma nacionalidade, e a "derivada" que seria combatida pela vedação de excisão ${ }^{32}$ de nacionalidade.

É uma demonstração, portanto, da imperatividade destas normas. Conforme coloca FRIEDRICH, o "jus cogens deve exprimir a conjugação dos valores de todas as diferentes visões da humanidade, ainda que esta não esteja representada em sua plenitude"33. Ainda, o fato da vedação à apatridia ser escrito numa declaração e não numa convenção pouco importa, pois, como fala FRIEDRICH "elas independem da forma pela qual se exteriorizam porque seu conteúdo é que vai diferenciá-las, haja vista que carregam em si os valores essenciais da sociedade internacional”34.

Deve-se somar a isto o valor da Declaração Universal, considerado integrante do Direito Internacional Consuetudinário para Antônio Augusto CANÇADO TRINDADE ${ }^{35}$. Ora, esteja prevista em texto normativo ou no costume internacional, o fato é que a prevenção da apatridia é norma imperativa de direito internacional, sendo vedado aos Estados desobedecer tal regra.

\footnotetext{
${ }^{32}$ Excisão é um ato de mutilação genital. A excisão feminina é um dos maiores problemas enfrentados por mulheres de muitos países. Tal procedimento impede a mulher, quando esta sobrevive, de ter qualquer prazer sexual. Na perda forçada de nacionalidade ocorre algo similar: os indivíduos são brutalizados, perdem uma parte fundamental de si, com chances parcas de recuperação. Eis a razão para o uso de tal termo.

${ }^{33}$ FRIEDRICH, Tatyana Scheila. As Normas Imperativas de Direito Internacional Público jus cogens, p.34.

${ }^{34}$ FRIEDRICH, Tatyana Scheila. As Normas Imperativas de Direito Internacional Público jus cogens, p.24.

${ }^{35}$ CANÇADO TRINDADE, Antônio Augusto. A Proteção Internacional dos Direitos Humanos e o Brasil (1948-1998), p.30.
}

Revista Brasileira de Direito Internacional, Curitiba, v.5, n.5, jan./jun.2007 


\section{DISPOSITIVOS LEGAIS}

Com o intuito de minimizar o drama dos apátridas e até a própria apatridia, foram celebrados diversos acordos internacionais, especialmente no âmbito das Nações Unidas. Além disso, diversos países e organismos regionais adotaram medidas para prevenir a apatridia ${ }^{36}$. No entanto, ainda há forte resistência a adoção de medidas uniformes de prevenção a apatridia, pois estas invariavelmente alterariam a própria legislação interna dos Estados, no que tange um de seus elementos constitutivos.

A primeira convenção voltada aos apátridas é o Estatuto dos Apátridas de 1954, que soluciona diversos problemas de ordem prática dos apátridas, como qual a lei aplicável em contratos e no estatuto pessoal e quais as condições e direitos trabalhistas. No entanto exclui do conceito de apátrida aquele que já receba algum outro apoio das Nações Unidas ${ }^{37}$, os criminosos comuns em certas ocasiões e aqueles que cometeram crimes contra a paz, de guerra e lesa humanidade e tais exclusões são a nosso ver, infrações a norma cogente de prevenção da apatridia.

É vedada a discriminação entre apátridas, bem como estes devem ter liberdade de culto e expressão na mesma medida do nacional do Estado onde se encontrem e nos demais direitos, devem ser tratados no mínimo como estrangeiros. Ou seja, devem ser respeitados, mas não necessariamente possuir uma relação privilegiada para com o Estado onde se encontram, o que os tornaria nacionais em certa medida.

Esta Convenção foi assinada por vinte e dois ${ }^{38}$ Estados e já conta com cinqüenta e quatro ${ }^{39}$ partes até a data de fevereiro de $2002^{40}$. Diversas

\footnotetext{
${ }^{36}$ Nesta seara o artigo 20,2 da Convenção de San Jose de Costa Rica, que prevê que todo indivíduo tem o direito a nacionalidade do país onde tiver nascido se não tiver direito a outra.

${ }^{37}$ UNITED NATIONS. Convention relating to the Status of Stateless Persons, art.2, (iii).

${ }^{38}$ Bélgica, Brasil, Colômbia, Costa Rica, Dinamarca, Equador, El Salvador, França, Alemanha, Guatemala, Santa Sé, Israel, Itália, Liechtenstein, Luxemburgo, Países Baixos, Noruega, Filipinas, Suécia, Suíça e Grã-Bretanha.

39 Argélia, Antígua e Barbuda, Argentina, Armênia, Áustria, Azerbaijão, Barbados, Bélgica, Bolívia, Bósnia Herzegóvina, Botsuana, Brasil, Chade, Colômbia, Costa Rica, Croácia, Dinamarca, Equador, El Salvador, Fiji, Finlândia, França, Alemanha, Grécia, Guatemala, Guiné, Santa Sé, Honduras, Hungria, Irlanda, Israel, Itália, Kiribati, Letônia, Lesoto, Libéria, Líbia, Liechtenstein, Lituânia, Luxemburgo, Madagascar, México, Paises Baixos, Noruega, Filipinas, Coréia do Sul, São Vicente e Granadinas, Eslováquia, Espanha, Suazilândia, Suécia,
}

Revista Brasileira de Direito Internacional, Curitiba, v.5, n.5, jan./jun.2007 
reservas foram feitas de maneira a proteger benefícios concedidos por Estados aos seus nacionais. Por exemplo, os Países Baixos reservaram a aplicação do artigo oitavo, que prevê restrições a medidas que possam ser tomadas contra um indivíduo simplesmente por sua respectiva nacionalidade anterior. O Reino reserva-se o direito de perseguir seus inimigos, o que é adotado em certo grau por outros Estados, como Barbados, Fiji, Finlândia, Kiribati, Suécia e Grã Bretanha. Outros Estados afastam a aplicabilidade da norma que prevê o tratamento mínimo como estrangeiro, por concederem privilégios a estrangeiros de determinados países. Assim, a Finlândia tratará o apátrida como estrangeiro, mas sem os benefícios que concede a nacionais do Pacto Nórdico (Dinamarca, Islândia, Noruega e Suécia).

Outra convenção fundamental para os apátridas é a Convenção Para Redução da Apatridia de 1961. Trata-se de uma Convenção mais extrema, pois prevê a concessão de nacionalidade através da extensão do ius soli ${ }^{41}$ e do ius sanguini ${ }^{42}$ para prevenir apatridia, sendo mínimos os casos em que se excetuam estas expansões. Portanto, trata-se de uma Convenção que obriga os Estados a alterarem suas leis internas de concessão de nacionalidade, um ato tradicionalmente delegado exclusivamente aos próprios Estados.

Ainda, a Convenção prevê a alteração de nacionalidade por causas do estatuto pessoal somente em casos em que se adquira a nova nacionalidade e determina a possibilidade de eventual reaquisição ${ }^{43}$. Um último importante dispositivo da Convenção é o artigo que afirma que "um Estado Contratante não pode privar qualquer indivíduo ou grupo de pessoas de sua nacionalidade por razões raciais, étnicas, religiosas ou políticas" ${ }^{\text {"4 }}$.

No entanto, poucos Estados participam desta Convenção. Cinco países assinaram $^{45}$ e vinte e seis ${ }^{46}$ fazem parte, impondo diversas reservas, em

Suíça, Macedônia, Trinidad e Tobago, Tunísia, Uganda, Grã Bretanha, lugoslávia, Zâmbia e Zimbábue.

${ }_{40}$ UNITED NATIONS. Treaty Collection [As of 5 February 2002].

${ }^{41}$ UNITED NATIONS. Convention on the Reduction of Statelessness, art.1.1.

${ }^{42}$ UNITED NATIONS. Convention on the Reduction of Statelessness, art.4.1.

${ }^{43}$ UNITED NATIONS. Convention on the Reduction of Statelessness, art. 5.1 e 5.2.

${ }^{44}$ UNITED NATIONS. Convention on the Reduction of Statelessness, art.9. Original em Inglês: "A Contracting State may not deprive any person or group of persons of their nationality on racial, ethnic, religious or political grounds." (traduzimos).

${ }^{45}$ República Dominicana, França, Israel, Países Baixos.

Revista Brasileira de Direito Internacional, Curitiba, v.5, n.5, jan./jun.2007 
especial o direito de retirar a nacionalidade conferida por força desta Convenção nos casos do ex-apátrida tornar-se um inimigo do Estado concedente. Tal espécie de reservas é, a nossa vista, correta, pois se trata da segurança interna do Estado que, numa ato de bondade concedeu sua nacionalidade, acolheu um indivíduo que depois num momento de ingratidão, torna-se um traidor.

Muitos Estados efetuam proteções internas para evitar a apatridia "nata" independente de legislação internacional. São exemplos o México, que adota tanto o ius soli quanto o ius sanguini ${ }^{47}$, El Salvador, que aplica também o ius soli e o ius sanguini ${ }^{48}$ sem restrições, Guatemala, que também protege tanto o nascido na Guatemala quanto o filho de guatemaltecas ${ }^{49}$. Outros países, como a Suécia ${ }^{50}$, prevêem a naturalização facilitada no caso dos apátridas com residência permanente no país. Podemos afirmar que muitos países buscam prevenir a apatridia "nata" através de atribuição do ius soli e dos ius sanguini, outros países buscam diminuir a apatridia através da naturalização facilitada, havendo, no entanto, certa discricionariedade, por tratar-se de ato administrativo soberano.

\footnotetext{
${ }^{46}$ Armênia, Austrália, Áustria, Azerbaijão, Bolívia, Bósnia Herzegóvina, Canadá, Chade, Costa Rica, República Checa, Dinamarca, Alemanha, Guatemala, Irlanda, Kiribati, Letônia, Líbia, Países Baixos, Níger, Noruega, Eslováquia, Suazilândia, Suécia, Tunísia, Grã Bretanha e Uruguai.

${ }^{47}$ MÉXICO. Constitución Política de los Estados Unidos Mexicanos, art.30, a, i e art.30, a, ii.

${ }^{48}$ EL SALVADOR. Constitución Política, art.90, 1 e 90,2.

${ }^{49}$ GUATEMALA. Constitución Política, art.144 e 145.

${ }^{50}$ SUÉCIA. Lag om svenskt medborgarskap, sec.6.
}

Revista Brasileira de Direito Internacional, Curitiba, v.5, n.5, jan./jun.2007 


\section{O CASO DOS "BRASILEIRINHOS APÁTRIDAS"}

A Constituição Brasileira de 1988 previa que eram brasileiros os nascidos no Brasil desde que não sejam filhos de indivíduos a serviço oficial estrangeiro, os nascidos fora do Brasil filhos de brasileiros em serviço oficial e os nascidos fora no Brasil desde que registrados em repartição competente ou que, mudando-se para o Brasil antes de completados 18 anos, optasse pela nacionalidade brasileira ${ }^{51}$. Estas eram as 3 hipóteses previstas na Constituição, podendo-se afirmar que havia a aplicação do ius soli mitigado, somado com o ius sanguini ${ }^{52}$.

No entanto, em infeliz e bizarra alteração legislativa, a Emenda Constitucional de Revisão número 3, de 1994 retira a última possibilidade, adicionando a possibilidade de aquisição de nacionalidade brasileira nata para aqueles que venham a residir no Brasil e optem pela nacionalidade brasileira, a "nacionalidade potestativa" 53 nas palavras de Alexandre de MORAES.

Ora, com o devido respeito pelo legislador e pelos defensores desta restrição ela é agressiva e antidemocrática, pois sequer foi discutida no congresso, conforme dizeres de Alexandre de MORAES:

\footnotetext{
"a análise das propostas apresentadas durante a revisão constitucional, bem como as emendas, substitutivos e pareceres ofertados, mostra que em momento algum o legislador constituinte-revisor pretendeu retirar do texto constitucional a hipótese, ${ }^{, 54}$.
}

No entanto, esta alteração teve um efeito ainda mais nefasto, pois sem esta possibilidade, muitos brasileiros não foram assim considerados pelo governo brasileiro, sendo apátridas "natos", recuperando seu direito a nacionalidade brasileira somente em 20 de setembro de 2007, com a Emenda Constitucional 54, que retoma a possibilidade do registro de brasileiros nascidos fora do Brasil, de brasileiros que não estejam a serviço oficial. Antes

\footnotetext{
${ }^{51}$ BRASIL. Constituição Federal, art. 12.

${ }^{52}$ Hoje se pode falar, por força da Convenção da Costa Rica, que o nascido no Brasil torna-se brasileiro mesmo se filho de diplomatas estrangeiros se no caso desta norma não ser aplicada, ocorresse apatridia. Os detalhes desta convenção foram vistos no capítulo anterior.

${ }^{53}$ MORAES, Alexandre de. Direito Constitucional, p.205.

${ }^{54}$ MORAES, Alexandre de. Direito Constitucional, p.207.
}

Revista Brasileira de Direito Internacional, Curitiba, v.5, n.5, jan./jun.2007 
disso, por orientação repassada aos consulados, era possível o "brasileiro apátrida" obter o passaporte brasileiro como documento de viagem, sem no entanto fazer prova da nacionalidade.

Esta foi a medida adotada após 13 anos de pressão política para reverter uma aberração legislativa. Para se exercer esta pressão, é fundamental ter o direito a voto e para isto, precisa-se da nacionalidade e da cidadania brasileiras. Caso não fosse corrigido a tempo, poderíamos não mais ter brasileiros interessados nesta correção, não seria eleitoralmente proveitoso alterar as leis. E teríamos brasileiros apátridas, com o perdão da contradição entre os dois termos.

Com a poeira se abaixando, o responsável pelo movimento dos Brasileirinhos apátridas, Rui MARTINS, publica notícia contando a "verdadeira história dos sem pátria", onde resumidamente expõe que a exclusão em 1994 da possibilidade do registro não foi um mero engano, mas uma medida feita para restringir a nacionalidade brasileira, mais precisamente aos filhos de emigrantes brasileiros no Japão ${ }^{55}$.

O relato feito por Martins é preocupante, pois o Brasil sempre foi um país que acolheu imigrantes, um país multicultural e de tolerância. Impedir o acesso ao Brasil por estes brasileiros que nasceram fora, por faltar a estes um elemento cultural brasileiro, uma ligação profunda com o Brasil é negar o próprio Brasil. Em primeiro lugar, porque se negava este direito aos filhos de brasileiros, uma geração consideravelmente próxima do Brasil, na imensa maioria dos países do mundo o ius sanguini é aceito ao menos até o primeiro grau de emigração.

Em segundo lugar porque negar aquele que nasceu fora do Brasil é negar a própria formação do povo brasileiro, o povo que dança samba, vai à Oktoberfest, joga capoeira, participa da festa do Haru-Matsuri, come pizza e macarronada. Somos um país onde se falam diversas línguas, onde se encontram pequenos pedaços de outros países, como os bairros da Liberdade e do Bixiga em São Paulo, as cidades de Blumenau e Nova Trento em Santa

\footnotetext{
${ }^{55}$ MARTINS, Rui. Revelação.
}

Revista Brasileira de Direito Internacional, Curitiba, v.5, n.5, jan./jun.2007 
Catarina, enfim, não podemos dizer que o Brasil é um país formado só por Brasileiros. 


\section{CONCLUSÃO}

A apatridia não merece espaço no cenário mundial. Precisam-se tomar medidas cada vez mais enérgicas e efetivas para prevenir a apatridia e minimizar a situação de desamparo que os apátridas são submetidos. Esta necessidade é reforçada pela imposição da prevenção à apatridia como norma cogente de direito internacional e por diversas convenções internacionais. No entanto, o maior obstáculo para a erradicação da apatridia está na resistência Estatal em alterar sua legislação para evitar a apatridia "nata", proibir a "derivada" e facilitar a naturalização dos apátridas.

A prática do Alto Comissariado das Nações Unidas para Direitos Humanos, tanto através da expedição de documentos de viagens, quanto da publicação de guias para parlamentares sobre a apatridia ${ }^{56}$, bem como as práticas estatais de naturalização em massa prestam grande serviço à humanidade. Não é correto considerar o apátrida criminoso, perigoso ou aproveitador (pois "ganharia" a nacionalidade do Estado). Pessoas notáveis, independente da posição política de cada um, foram ou são apátridas, dentre as quais listamos: Albert Enstein, Friedrich Nietzsche, Anne Frank e Karl Marx. Negar crédito a estes indivíduos pelo fato da apatridia é impor um estigma desnecessário e, no mínimo, imbecil.

\footnotetext{
${ }^{56}$ UNITED NATIONS HIGH COMISSIONER FOR HUMAN RIGHTS. Nationality \& Stateless. $A$ Handbook for Parlamentarians.
}

Revista Brasileira de Direito Internacional, Curitiba, v.5, n.5, jan./jun.2007 


\section{REFERÊNCIAS}

ARMÊNIA. The Law of the Republic of Armenia on Political Asylum. 19.10.2001. AL-229.

AUDIT, Bernard. Droit International Privé. Paris: Economica, 2006, 4aa edição. Corpus Droit Prive, Dirigé par Nicolas Molfessis.

BRADLEY, Anthony W; EWING, Keith D. Constitutional and Administrative Law. London; New York: Addison Wesley Longman, 1993, 11a edição, 6ª impressão.

BRASIL. Constituição Federal.

BUSTAMANTE Y SIRVEN, Antonio Sanchez de. Derecho Internacional Privado. Habana: Cultural, 1943, tomo 1, 3ª edição.

CANÇADO TRINDADE, Antônio Augusto. A Proteção Internacional dos Direitos Humanos e o Brasil (1948-1998). Brasília: Universidade de Brasília, 2000, $2^{\text {a }}$ edição. Série Prometeu.

CAZAQUISTÃO. Presidential Decree of 15th July 1996.

CONVENÇÃO DE DIREITO INTERNACIONAL PRIVADO (CÓDIGO BUSTAMANTE), Habana, 1928

CONVENTION ON CERTAIN QUESTIONS RELATING TO THE CONFLICT OF NATIONALITY LAWS, Den Haag, 1930.

CONVENTION ON THE LAW OF TREATIES, Wien, 1969.

CONVENÇÃO AMERICANA DE DIREITOS HUMANOS, San José de Costa Rica, 1969.

DIXIT, Himali. Repatriation or resettlement. Resolving the Lhotshampa dilemma. Himal Southasian. Special Report june 2007. Disponível Online em: < http://www.himalmag.com/2007/june/special_report_bhutanese_refugees.htm>. Acesso em 24.10.2007, 06:09.

EL SALVADOR. Constitución Política.

FRELICK, Bill. Bhutanese Refugees: The Right of Return, the Chance for Resettlement. The Huffington Post, 20 de junho de 2007. Disponível Online em: $<$ http://www.huffingtonpost.com/bill-frelick/bhutanese-refugees-the_b_53090.html>. Aceso em 25.10.2007, 23:50

FRIEDRICH, Tatyana Scheila. Normas Imperativas de Direito Internacional Privado lois de police. Belo Horizonte: Fórum, 2007.

Revista Brasileira de Direito Internacional, Curitiba, v.5, n.5, jan./jun.2007 
FRIEDRICH, Tatyana Scheila. As Normas Imperativas de Direito Internacional Público jus cogens. Belo Horizonte: Fórum, 2004.

GUATEMALA. Constitución Política.

HUMAN RIGHTS WATCH. Buthanese Refugees Rendered Stateless (Human Rights Watch, 18-6-2003). Disponível Online em: < http://hrw.org/english/docs/2003/06/18/nepal6160.htm> . Acesso em 24.10.2007, 10:14.

HUMAN RIGHTS WATCH. World Report 2001: Childrens's Rights - Refugee, Immigrant and Stateless Children . Disponível Online em: <http://www.hrw.org/wr2k1/children/child3.html> . Acesso em 24.10.2007, 11:11

HUMAN RIGHTS WATCH . World Report 2002: Children's Rights. Disponível Online em: <http://www.hrw.org/wr2k2/children.html\#Refugee and Migrant Children>. Acesso em 24.10.2007, 12:40.

MARTINS, Rui. Revelação. Disponível Online em : < http://www.brasileirinhosapatridas.org/revela.htm>. Acesso em 23.10.2007, 23:45.

MAYER, Pierre ; HEUZÉ, Vincent. Droit International Prive. Paris: Montchrestien ; Librairie Générale de Droit et Jurisprudence (LGDJ), 2004, 8 a edição.

MÉXICO. Constitución Política de los Estados Unidos Mexicanos.

MORAES, Alexandre de. Direito Constitucional. São Paulo: Atlas

REILLY, Rachel. Nepal: Buthanese Refugees Rendered Stateless. In: HUMAN RIGHTS WATCH. Buthanese Refugees Rendered Stateless (Human Rights Watch, 18-6-2003). Disponível Online em: < http://hrw.org/english/docs/2003/06/18/nepal6160.htm>. Acesso em 24.10.2007, 10:00.

SUÉCIA. Lag om svenskt medborgarskap, 2001, 82. Näringsdepartementet, 2001-03-01.

UNITED NATIONS. Convention on the Reduction of Statelessness. Adopted on 30 August 1961 by a conference of plenipotentiaries which met in 1959 and econvened in 1961 in pursuance of General Assembly resolution 896 (IX) of 4 December 1954.

UNITED NATIONS. Convention relating to the Status of Stateless Persons. Adopted on 28 September 1954 by a Conference of Plenipotentiaries convened by Economic and social Council resolution 526 A (XVII) of 26 April 1954. 
UNITED NATIONS. Treaty Collection [As of 5 February 2002]. Disponível Online em: < http://www.unhchr.ch/html/menu3/b/treaty3stat.htm>. Acesso em 22.10.2007, 15:40.

UNITED NATIONS, Universal Declaration of Human Rights. Adopted and Proclaimed by General Assembly resolution 217 A (III) of 10 December 1948.

UNITED NATIONS HIGH COMISSIONER FOR HUMAN RIGHTS. Nationality \& Stateless. A Handbook for Parlamentarians. Disponível Online em : < http://www.unhcr.org/protect/PROTECTION/436774c62.pdf>. Acesso em 24.10.2007, 14:00.

Revista Brasileira de Direito Internacional, Curitiba, v.5, n.5, jan./jun.2007 